\title{
Cuidados Necessários à Infância: Um Estudo com Mães Coletadoras de Material Reciclável
}

\author{
Shana Hastenpflug Wottrich ${ }^{1}$ \\ Programa de Pós-Graduação em Psicologia da Universidade Federal de Santa Catarina, \\ Florianópolis, Santa Catarina, Brasil \\ Dorian Mônica Arpini \\ Departamento de Psicologia da Universidade Federal de Santa Maria, Santa Maria, \\ Rio Grande do Sul, Brasil
}

\begin{abstract}
Resumo
As atribuições dos papéis parentais, no que concerne às contribuições para o desenvolvimento de seus filhos, são questões a serem analisadas tendo em vista os contextos sociais e históricos, considerando as relações construídas em cada meio familiar. Nessa perspectiva, a presente pesquisa objetivou compreender os significados acerca dos cuidados necessários à infância atribuídos por mães de grupos populares. Foram realizadas oito entrevistas semi-estruturadas com mães de filhos de 0 a 6 anos, que tinham como principal trabalho as atividades de coleta e a seleção de material reciclável. Os dados foram analisados através da análise de conteúdo. As mães manifestaram preocupação acerca do estabelecimento de uma relação de proximidade no contato com seus filhos. Observaram-se atitudes ambivalentes com relação às estratégias utilizadas na educação das crianças, bem como a identificação de uma rede de apoio que oferece suporte no manejo dos cuidados a eles dispensados. Evidencia-se a preocupação materna quanto à transmissão de valores e práticas educativas permeadas pela ética do que é certo/honesto e, portanto, esperado para os filhos. Entende-se que os resultados desse estudo podem subsidiar reflexões na direção da construção de propostas de intervenções, para profissionais que trabalham na área da saúde da criança, no sentido da promoção da saúde.
\end{abstract}

Palavras-chave: Desenvolvimento infantil, cuidado materno, educação, relações familiares.

\section{Care Required Throughout Childhood: A Study with Mothers who Collect Recyclable Material}

\begin{abstract}
The parental roles regarding contributions to the development of their children are matters to be analyzed in the light of social and historical contexts, considering the relationships built in particular family environments. In this perspective, this research aimed to understand the meanings about care required in childhood attributed by mothers of popular groups. Eight semi-structured interviews were carried out with women who were mothers of children aged 0-6 years old and who worked collecting and selecting recyclable material. Data were analyzed through content analysis. Mothers reported the relevance of establishing a close relationship with their children. Ambivalent attitudes related to strategies used for the education of the children were observed, as well as the identification of a support network that
\end{abstract}

Endereço para correspondência: Laboratório de Psicologia da Saúde, Família e Comunidade, Centro de Filosofia e Ciências Humanas, Universidade Federal de Santa Catarina, Campus Universitário - Trindade, Florianópolis, SC, Brasil 88040-500.E-mail: shana.wottrich@gmail.com e monica.arpini@gmail.com 
provides support concerning care towards the children. Education practices are guided by the concern of the mothers about putting forward education values and practices embedded in the ethical values of what is considered right/honest and, therefore, expected for the children. The results of this study may subsidize reflections in the direction of creating intervention proposals for professionals whose work relates to child health care, in the sense of health promotion.

Keywords: Child development, parental care, education, family relations.

\section{Cuidados Necesarios con la Niñez: Un Estudio de las Madres Colectoras de Materiales Reciclables}

\section{Resumen}

Las atribuciones de los papeles parentales, en términos de contribución al desarrollo de sus hijos deben ser analizadas a la luz de los contextos sociales e históricos, teniendo en cuenta las relaciones establecidas en cada entorno familiar. En esta perspectiva, el presente estudio tuvo como objetivo comprender los significados sobre los cuidados necesarios con la niñez, atribuidos por las madres de grupos populares. Fueron hechas ocho entrevistas semi-estructuradas con mujeres madres de niños de 0-6 años de edad, cuya principal actividad de trabajo era la recolección y la selección de materiales reciclables. Se analizaron los datos mediante el método de análisis de contenido. Las madres expresaron la importancia de establecer una relación de proximidad con sus hijos. Se observaron actitudes ambivalentes con respecto a las estrategias utilizadas en la educación de los niños, así como la identificación de una red de apoyo que les ofrece soporte en la gestión de la atención dispensada a los mismos. Es evidente, por tanto, la preocupación de la madre con respecto a la transmisión de los valores y prácticas educativas impregnadas por la ética de lo que es cierto/honesto y por lo tanto, esperado para los niños. Se entiende que los resultados de este estudio pueden subsidiar reflexiones para la construcción de propuestas de intervenciones para los profesionales que trabajan en el área de la salud de los niños, en el sentido de la promoción de la salud.

Palabras clave: Desarrollo infantil, cuidado de la madre, educación, relaciones familiares.

Abordar a temática da família e dos cuidados parentais exige, daquele que se ocupa desta tarefa, distanciamento, a fim de evitar projetar um modelo familiar específico, frequentemente aquele com o qual o pesquisador está identificado, como sendo universal. Tal projeção pode levar a naturalizar e a normatizar a compreensão do que se passa no contexto de vida das famílias, obscurecendo as importantes diferenças entre elas (Sarti, 2004). No sentido de assumir um posicionamento contrário a esse processo de naturalização, neste estudo, entende-se ser imprescindível contextualizar as experiências vivenciadas pelos participantes da pesquisa. Indo nessa direção, propõe-se, a seguir, uma caracterização do cenário de vida dos participantes do presente estudo.
A provisão de renda por meio da coleta e seleção de materiais recicláveis, atividade desempenhada pelos participantes da pesquisa apresentada neste artigo, pode ser concebida como fruto de um processo de exclusão social, diretamente influenciado pelos moldes da sociedade de consumo (Bosi, 2008). Os sujeitos envolvidos nessas atividades buscam nelas formas de subsistir a um processo de precarização do trabalho, encontrando na informalidade uma forma de sobreviver e sustentar financeiramente a si mesmos e à família (Medeiros \& Macêdo, 2006). Os "catadores" de material reciclável caracterizam-se, em geral, pelo baixo nível de escolaridade, ausência de vínculo empregatício e reconhecimento de seus direitos trabalhistas. Recebem menos de um salário mínimo por mês e sobrevivem em condições precárias de saúde, de moradia e de alimentação (Bortoli, 2009). Tratam-se de pes- 
soas, portanto, que vivem à margem da sociedade, em situação de pobreza.

Neste estudo, entende-se "pobreza" como um fenômeno complexo e multidimensional, como manifestação de questões sociais, fruto das relações desiguais constitutivas da sociedade capitalista. Sob essa ótica, a pobreza não se restringe unicamente ao plano financeiro, ao acesso a bens, mas diz respeito à carência de oportunidades, direitos e possibilidades. Trata-se de um modo específico de inserção na vida social, a uma condição de classe, social e historicamente construída, em cujo contexto o "pobre" é desqualificado em suas crenças, sua forma de expressão e seu comportamento, sendo a ele culturalmente atribuídos valores negativos (Yazbek, 2012).

No sentido de caracterizar a pobreza, no cenário brasileiro, dados do Instituto Brasileiro de Geografia e Estatística (IBGE), apontam a desigualdade da distribuição de renda no país. Essa desigualdade aparece marcadamente com um padrão de cor ou raça, de forma que, em 2012, dentre os $10 \%$ mais pobres, estavam $14,1 \%$ da população preta ou parda e 5,3\% dos brancos. $\mathrm{Na}$ direção oposta, os brancos ocupavam os estratos superiores de rendimentos, havendo uma pequena participação de pretos ou pardos (IBGE, 2013).

Em termos de desenvolvimento de uma criança, sabe-se que a pobreza atua como fator de risco, tornando os sujeitos vulneráveis quanto à manutenção de sua saúde física e mental. No entanto, mediante determinados fatores protetivos (recursos que pertencem à criança, seu entorno, ou ambos), pode haver o amortecimento do efeito dos fatores de risco, de forma a amenizar ou impedir resultados negativos. Cumpre destacar que os fatores de proteção podem ser desenvolvidos ou potencializados por meio das relações estabelecidas por estas crianças com o seu entorno, através da criação de um meio-ambiente positivo (Oros, 2009).

À luz dessa contextualização, buscando aportes para a compreensão dos cuidados necessários à infância, no contexto de famílias de grupos populares brasileiros, salienta-se o papel da família na constituição da criança como su- jeito, já que é por meio da construção dos vínculos familiares que ela entra em contato com a alteridade (Szymanski, 2004). A importância das primeiras relações estabelecidas com/pela criança reside no fato de que é através dessas relações (comumente com as figuras parentais), que a criança desenvolve recursos para o enfrentamento de situações difíceis ao longo de seu desenvolvimento (Richaud de Minzi, 2004).

Assim, em contexto de grupos populares, sendo pai e/ou mãe os responsáveis pelo sustento financeiro e funcional do lar, conforme pesquisa de Peres (2001a), fica evidente a necessidade de proteção dos filhos e de provisão de educação para eles, almejando que isso impeça a repetição das dificuldades e características ruins da vida dos pais. Segundo essa mesma pesquisa, acerca da afetividade, dos vínculos entre os membros da família, a atenção, a aproximação e o carinho de uns com os outros fazem parte da concepção de uma família ideal. Em outros termos, para os pais entrevistados, a construção de relações com seus filhos deve ser realizada sob a égide da afetividade.

Considera-se, ainda, que a noção de família é ampliada para uma rede de suporte que inclui a vizinhança e o bairro (Bilac, 2002). Assim, é tecida uma rede de sustentação que dá conta do suprimento das necessidades mais emergenciais (Polli \& Arpini, 2012a), atuando como fator que contribui ou pode contribuir para o enfrentamento de adversidades frequentemente presentes em contextos de pobreza (Yunes, Garcia, \& Albuquerque, 2007). Tais ideias contrariam as concepções preconceituosas, que, de forma simplista, desconsideram a força dos sentimentos nas relações entre os membros desse grupo social (Polli \& Arpini, 2012a; Silva, Polli, Sobrosa, Arpini, \& Dias, 2012).

Complementando a caracterização desse cenário, percebe-se uma ampliação na divisão de responsabilidades quanto às tarefas que concernem à criação e à educação dos filhos. Tais responsabilidades passam a ser percebidas como compartilhadas pelos pais (Wagner, Predebon, Mosmann, \& Versa, 2005), assim como as atividades de sustento financeiro, em decorrência da participação da mulher no mercado de tra- 
balho (Monteiro \& Cardoso, 2001; Wagner \& Levandowski, 2008). Em relação a este aspecto, estudos têm evidenciado a importância das mães no contexto familiar, sendo expressivo o número de lares chefiados por mulheres, as famílias monoparentais femininas, nas quais a mulher/mãe acumula as funções de sustento econômico, funções domésticas e cuidado com os filhos (Kehl, 2008).

Apesar da mulher, ao longo do tempo, estar mais presente no espaço público, sendo identificada pela sua força de trabalho, no contexto dos grupos populares, sustenta-se o lugar hierárquico superior socialmente atribuído ao homem, como chefe de família (Romanelli, 2002), sendo atribuição da esposa a manutenção do equilíbrio e união do grupo doméstico. O cuidado relacionado à nutrição (Wagner et al., 2005) e à socialização dos filhos (Monteiro \& Cardoso, 2001; Romanelli, 2002) ainda continuam primordialmente sob responsabilidade da mulher, bem como a aparente mediação e representação do pai (Romanelli, 2002). Paradoxalmente à suposta manutenção do lugar hierárquico paterno, salienta-se que, embora a autoridade paterna exista, ela não se mostra de forma absoluta (Arpini, Quintana, \& Gonçalves, 2010; Romanelli, 2002). Tal autoridade pode ser questionada e rejeitada dependendo das relações de força entre os membros da família, permitindo relações mais igualitárias. Complementando esse cenário, evidencia-se a existência da autoridade materna, fundada na afetividade (Arpini et al., 2010; Polli \& Arpini, 2012b). Considera-se, assim, o papel materno de interlocução, sendo a mãe concebida como aquela digna de confiança para que os filhos possam partilhar seus problemas. "Uma boa mãe", nesse sentido, seria aquela que está sempre perto dos filhos, que deixa de seus próprios interesses para cuidá-los (Bustamante \& Trad, 2007).

No tocante às práticas utilizadas para o cuidado e a educação dos filhos, tem lugar de destaque a prática da coerção física, percebida, por vezes, como o único meio de disciplinamento e afirmação de preocupação, amor e cuidado por parte dos pais, mas não, necessariamente, como a estratégia ideal (Bustamante \& Trad,
2007; Oliveira, Rabuske, \& Arpini, 2007). Nesse contexto, verifica-se que os pais mostram-se carentes de recursos para mediatizar suas relações com os filhos, situação em que emerge a ansiedade pela busca de parâmetros que possam servir como balizadores das relações (Silva et al., 2012). Trata-se de uma realidade multidimensional e multideterminada, em que se verifica o atravessamento de vários fatores, culminando com a fragilização das funções parentais. Assim, decorre da dificuldade de disciplinar os filhos e de colocar limites claros, o aumento da permissividade em relação a eles, evidenciando complicações no manejo da posição de autoridade (Zanetti \& Gomes, 2011).

E relevante considerar, na análise das relações supracitadas, independentemente das dificuldades enfrentadas, o sentido de proteção atribuído à família. Observa-se, no contexto das famílias de grupos populares, a emergência da violência, não apenas praticada em atos concretos, mas também presente na vivência de vulnerabilidade social, através das diferenças de oportunidades. Assim, são as relações familiares que sofrem o impacto da tensão ocasionada pela carência de recursos materiais para fornecer os cuidados mais básicos às crianças, sendo, ao mesmo tempo, atribuído ao núcleo familiar o papel de amenizar esta situação (Arpini et al., 2010).

No marco dessas considerações, este estudo teve como objetivo compreender os significados acerca dos cuidados necessários à infância atribuídos por mães de periferia urbana, cuja atividade profissional consistia na coleta e seleção de material reciclável.

\section{Método}

\section{Delineamento}

Trata-se de um estudo qualitativo, exploratório e descritivo. A modalidade metodológica qualitativa prioriza a consideração dos aspectos singulares e complexos da vida humana, remetendo aos significados que os sujeitos atribuem às suas ações e relações, na tentativa de compreender os sentidos dos atos e das decisões deles (Chizzotti, 1998; Minayo, 2010). O caráter 
exploratório e descritivo da pesquisa, por sua vez, refere-se à busca de uma aproximação ao problema investigado, objetivando contribuir para a delimitação da temática de estudo e para o aprofundamento dos seus conceitos. Envolve a exploração e a descrição das características de um fenômeno específico (Sampieri, Collado, \& Lucio, 2006).

\section{Participantes}

As participantes da pesquisa tinham como fonte de renda a atividade de coleta e seleção de material reciclável e faziam parte de um projeto da Secretaria Municipal de Cultura em parceria com a Secretaria de Proteção Ambiental da prefeitura de um município do interior do estado do Rio Grande do Sul. Tal projeto incluía a realização de oficinas de diversas atividades com os trabalhadores. Os contatos com as possíveis participantes foram feitos por uma das pesquisadoras, através da mediação da coordenadora do projeto, antes da realização de encontros das oficinas. Os convites para a participação na pesquisa foram realizados de forma coletiva, expondo riscos, benefícios e demais informações eticamente relevantes, solicitando a participação voluntária das mulheres. Foram realizadas combinações específicas com aquelas dispostas a participarem acerca do local, do dia e do horário mais convenientes para a realização das entrevistas individuais.

Foram entrevistadas oito mulheres entre 22 e 42 anos de idade, com ensino fundamental incompleto, sendo que seis viviam em situação de co-habitação com um companheiro, uma vivia apenas com os filhos e a outra com os filhos e netos. Dessas, duas tinham dois filhos, duas tinham três filhos, duas tinham cinco filhos e duas tinham seis filhos. Uma das mulheres entrevistadas foi incluída na pesquisa por desempenhar a função materna para seus netos biológicos, estando inclusive com a guarda judicial de um deles. Essa mulher vivia em situação de co-habitação com seis filhos e sete netos biológicos.

Entendeu-se que, para os fins da pesquisa, as entrevistadas deveriam auto-denominar-se como desempenhando a função materna. Essa questão mostra-se independente da existência de laços consanguíneos, já que como coloca Bilac (2002) a função de maternagem é algo construído e não dado a priori. Ainda, no mínimo um dos filhos deveria ter idade inferior a seis anos. Essa condição mostrou-se pertinente à medida que é na idade de zero a seis anos - antes do ingresso na escola - que o convívio com a família é mais próximo, além de ser esse um período caracterizado pela socialização primária (característica importante para o desenvolvimento infantil, segundo Monteiro \& Cardoso, 2001).

\section{Técnicas e Procedimentos de Coleta de Dados}

Entrevistas semiestruturadas foram utilizadas como instrumento de coleta de dados, em função da pressuposição de que elas possibilitam a expressão e comunicação fidedignas dos informantes acerca de suas experiências, representações, concepções e ideias (Chizzotti, 1998). Foram entrevistadas oito participantes, individualmente, seguindo indicações do critério de saturação dos dados, segundo o qual quando os dados coletados deixam de ser novos e configurar estrutura comum sobre o tema estudado, finaliza-se a coleta de dados (Fontanela, Ricas, $\&$ Turato, 2008). Antes da realização de cada entrevista era retomado o objetivo da pesquisa, bem como pedido o consentimento para a gravação da entrevista em áudio e participação na pesquisa em concordância com as normas que regulamentam a pesquisa com seres humanos. Ratifica-se que o estudo foi conduzido em conformidade com a Resolução 196/96, do Conselho Nacional de Saúde.

Considerando-se os apontamentos de Minayo (2010) acerca da obtenção de informações, produziu-se um roteiro de entrevista que continha tópicos estabelecidos de acordo com a problemática de interesse. Assim, os eixos temáticos que nortearam as entrevistas foram: os cuidados identificados como necessários ao desenvolvimento dos filhos, os problemas apresentados ao longo do desenvolvimento de uma criança e as alternativas utilizadas para solucionar os obstáculos apresentados. 


\section{Técnicas e Procedimentos de Análise dos Dados}

Por tratar-se de uma pesquisa qualitativa, convém ressaltar a importância da consideração de todos os fenômenos que circunscrevem os sujeitos, suas manifestações e ocasionalidade, bem como as interrupções e o silêncio, sendo necessário analisar e revelar significados manifestos e latentes (Chizzotti, 1998; Minayo, 2012). Posto isso, optou-se por utilizar como referência a análise de conteúdo temática proposta por Bardin (1977/2008). A análise de conteúdo temática é aquela que tem o tema como conceito central, buscando desvelar as unidades ou núcleos de sentido que compõem a comunicação (Bardin, 1977/2008; Gomes, 2012). Assim, tem-se como objetivo uma interpretação mais profunda da comunicação, não pela verificação da frequência com que falas e palavras aparecem, mas pela compreensão dos significados no contexto da fala (Minayo, 2012). Reduzindo o volume de informações contidos nas entrevistas a categorias conceituais, procurou-se interpretar e investigar a compreensão dos sujeitos entrevistados acerca de seu contexto e as influências dele na forma e conteúdo comunicado, conforme referencia Chizzotti (1998).

Dessa forma, inicialmente, em decorrência da leitura de cada entrevista individualmente e posteriormente do conjunto do material, pode-se obter uma familiarização com os dados obtidos, dos quais emergiram as categorias e subcategorias temáticas que contemplam elementos, ideias e expressões com características comuns e relacionadas entre si, considerando a força discursiva, os sentimentos manifestos, os silêncios e os conflitos ao abordar o tema. Destaca-se que o procedimento de categorização acima descrito foi realizado através de uma análise realizada num primeiro momento, individualmente, por cada pesquisador e, posteriormente, em conjunto. As referidas categorias serão apresentadas junto a recortes das narrativas das participantes, para fins de ilustração, sendo elas identificadas por $M 1,2,3 \ldots$ remetendo à Mãe $1,2,3, \ldots$ seguido da idade.

\section{Resultados e Discussão}

A integração dos dados, oriunda da análise, gerou as categorias que serão descritas e discutidas a seguir: "Educação e cuidado: O Ensino de Valores em Questão", "Estratégias para o Ensino de Normas/Valores" e "O Enfrentamento das Dificuldades: Redes de Apoio”.

\section{Educação e Cuidado: O Ensino de Valores em Questão}

No universo de representações das entrevistadas, a questão da educação das crianças como atribuição da família foi preponderante. Sendo a educação dos filhos um dos papéis culturalmente e historicamente assumidos pelas mulheres (Costa, 1983), a responsabilização das mães nesse sentido é um ponto que deve ser considerado (Peres, 2001a). "Olha, eu tenho que mostrar pra eles o caminho, o caminho certo. Porque assim, né... Agora eu que tenho responsabilidade de cuidar deles, de proteger eles, em relação a várias coisas" (M4, 22).

Na narrativa descrita, evidencia-se a ligação entre as noções de responsabilização, cuidado e proteção, referidas como atribuições do papel materno. Somado a isso, no que diz respeito aos valores considerados imprescindíveis no contexto da criação dos filhos, a questão da obediência, principalmente em relação aos pais, teve papel de destaque. "Pros pequenos o mais importante é a educação começar . . . Eu acho mais importante. Que eles tem que obedecer principalmente os mais velhos" (M5, 38).

No sentido explicitado, é possível inferir a concepção de que, justamente por essa ser uma fase em que o desenvolvimento está iniciando, o exercício da autoridade por parte dos pais é necessário (Romanelli, 2002), considerando que a criança é desprovida de capacidade de julgar sobre o que é melhor para si. Assim, emerge nos relatos a representação dos ensinamentos de valores como forma de proteção diante da ingenuidade e fragilidade da criança frente ao mundo, conforme ilustra a narrativa a seguir.

$E$ E, a gente tem que estar sempre cuidando, alertando: "Não faz isso! Isso é bom! Isso 
é ruim!" Tem que desde pequenininho ficar falando. Então tem que estar sempre ensinando, porque eles não sabem a noção do perigo, o que é bom, o que não é. Então, a gente tá sempre dizendo o que é bom, o que não é... (M8, 30)

Na direção de compreensão dessa narrativa, Moinhos, Lordelo e Moura (2007), em pesquisa realizada com mães baianas de diferentes níveis socioeconômicos, afirmam que elas consideram ser papel da mãe os cuidados afetivos e cognitivos, tais como: dar exemplo, orientar o que é certo e o que é errado, dar amor e carinho. Cumpre destacar que os resultados da referida pesquisa, quando analisados de forma geral, apontam que as metas de mães de diferentes níveis socioeconômicos, quanto à socialização dos filhos, não diferiram significativamente, salientando que os valores idealizados para a educação dos filhos eram similares, independentemente do grupo social a que pertenciam as mulheres participantes. Segundo os autores, esse resultado pode estar retratando expectativas de um ambiente cultural relativamente homogêneo quanto a valores idealizados.

Concomitantemente, tal estudo também destacou que, para as mães de nível socioeconômico baixo, as metas de socialização relacionadas ao bom comportamento são mais valorizadas do que para as mães de nível socioeconômico mais alto. Embora tal diferença encontrada não tenha sido estatisticamente significativa, aponta para a valorização da obediência e de prescrições sociais por parte desse grupo (Moinhos et al., 2007). Considerando que tais valores também são enfatizados nesta categoria, esses dados podem ser compreendidos mediante contextualização das experiências de mães de grupos populares. Através da valorização do ensino do "bom comportamento", as mães estariam tentando mostrar que ser "pobre" não é sinônimo de ter comportamentos socialmente reprováveis, esforçando-se para contrariar as "qualidades negativas" socialmente atribuídas a essa classe social (Yazbek, 2012).

Em síntese, constata-se, nessa categoria, a noção de que a infância é uma etapa marcada pela vulnerabilidade e pela fragilidade. Portanto, a criança necessita do espelhamento do adulto para se referenciar, sendo essa tarefa, na percepção das mães deste estudo, uma atribuição de quem exerce a função parental, através de estratégias específicas.

\section{Estratégias para o Ensino de Normas/Valores}

No universo dos significados das entrevistadas, a questão da educação das crianças é marcada pela instauração de um paradigma, a saber: as mães parecem relatar certa confusão com relação aos parâmetros que devem utilizar, relacionados a estratégias para educação de seus filhos (Oliveira et al., 2007). Nesse escopo, dois pólos e duas concepções de práticas são instaurados: o da intervenção verbal e o da coerção física.

No presente estudo, a conversa ou o diálogo estiveram quase unanimemente subjacentes às falas das mães como algo ideal, que deve sempre ser priorizado, concordando com o estudo de Bustamante e Trad (2007). A narrativa a seguir ilustra essa ideia. " $E$ falando com calma. Eu falo com calma com eles. Ai se eles teimam fazer, aí a paciência termina. Ai tem que falar mais grosso. Ai eles escutam, mas por uns minutos só" (M5, 38).

Com base nessa narrativa, depreende-se que a referida "calma" deve estar idealmente presente no diálogo com os filhos, o que nem sempre acaba acontecendo nas vivências relatadas. Assim, ao versar sobre as formas assumidas pelas intervenções verbais, as mães apontam a temática da exacerbação dos ânimos, a "perda de paciência", como permeando suas práticas educativas. As intervenções maternas parecem iniciar sob a caracterização de uma "conversa" ou "explicação", evoluindo para práticas mais coercitivas (Oliveira et al., 2007), caso não se sintam escutadas, conforme o depoimento a seguir.

$E$, conversando, explicando: isso aqui é nesse lugar e não é pra tirar. É aqui que fica... Quando saem não dizer nome, não dizer palavrão pras pessoas, né. Então vai... A gente tem que ter, né, muito o que ensinar, desde pequeno. Não é fácil. . . Então, tem que desde pequenininho, ensinando aos pouquinhos. Porque não é da noite pro dia que vão aprender. Mas eles podem voltar a 
fazer e se ralhar e repreender na segunda vez, na terceira vez já não faz. (M8, 30)

A narrativa supramencionada ilustra a compreensão de que o ensino do discernimento entre certo e errado é um processo contínuo, que progride ao longo do tempo e que pode passar por estratégias diversas, na tentativa de afirmação de valores aos filhos. Agrega-se a essas concepções, a ideia de que intervenções verbais nem sempre se colocam como as mais eficazes diante da desobediência de um filho, aparecendo nas narrativas das participantes associações diretas entre essa estratégia e a coerção física, embora as mães julguem que a coerção física não é a prática mais adequada (Bustamante \& Trad, 2007). A narrativa a seguir aponta nessa direção de entendimento.

Olha, castigo eu não sei se dá pra dar. Então, eu, no meu caso, eu mais converso. Procuro não surrar, mas eu acho que eu vou ter que passar o laço nele, senão não... Então, tudo que ele pede pra mim, eu dou, pra ver se eu consigo... Ele acha que é só ele, no caso, eu tenho que dar só pra ele, pros outros, não... É ai que ele se provalece... Mas eu acho que a gente tem que botar no castigo, bater, pra poder... Tem que dar laço, senão não tem medo da gente... Agora, do pai dele, ele já tem medo. O pai dele bate nele. E eu passo mais na rua. Quando eu chego em casa, ele começa... Aí o pai dele diz: "Tua mãe chega em casa e tu incomoda". Então, no caso, é a minha, é falta de eu surrar ele, de eu querer... E eu tenho pena e não bato. (M7, 35)

Depreende-se dessa narrativa, a ideia de que a utilização da coerção física é a que repercute em resultados, por vezes, mediante a ineficácia das demais estratégias. Evidencia-se, assim, uma situação de falta de parâmetros quanto a estratégias para a educação dos filhos. Se por um lado, as mães percebem que a verbalização pode resolver os conflitos com os filhos de forma mais tranqüila, por outro, fica evidente a concepção de que há momentos em que a utilização da estratégia verbal não dá conta, de que é necessário algo concreto. Em concordância, Oliveira et al. (2007) identificaram o uso da estratégia coerci- tiva nas situações em que as mães julgaram ter perdido o autocontrole. Na presente pesquisa, tal estratégia é apontada como o ponto final de um processo gradual, que vai do conversar e explicar, culminando com o bater. "Eu converso e se eles não vão pela conversa, dai tem um ponto que chega que tem que bater" (M5, 38).

Em síntese, constata-se, nessa categoria, que as mães assumem posições ambivalentes sobre as estratégias a serem utilizadas para a educação dos filhos. Tais posições parecem ser atravessadas pelos desígnios do que é socialmente aceito, pelas negociações de papeis e funções no seio familiar e pelas relações singulares estabelecidas com cada filho. A educação dos filhos, assim, caracteriza-se como uma seara em que emergem múltiplas dificuldades, que são enfrentadas mediante $\mathrm{o}$ acesso a redes de apoio.

\section{O Enfrentamento das Dificuldades: Rede de Apoio}

O enfrentamento das dificuldades na manutenção dos cuidados, tanto no que se tange à provisão de recursos materiais quanto afetivos, parece possível mediante o aporte na rede de apoio familiar, considerando-se a noção de família ampliada, bastante presente em contextos de classes populares (Monteiro \& Cardoso, 2001; Polli \& Arpini, 2012a). Fizeram-se presentes nas narrativas a importância da presença do marido, da avó materna e dos filhos mais velhos, em relação à provisão de cuidados.

A importância da presença do pai das crianças ou de um companheiro aparece com um sentido principal, que diz respeito, preponderantemente, ao sustento econômico, sendo que a subsistência da família parece ser possibilitada mediante a soma de esforços de ambos os membros do casal para angariar recursos financeiros (Wagner et al., 2005). Assim sendo, quando um dos pais falta, as dificuldades para manutenção das condições básicas de sobrevivência aumentam.

Já passei... Eu criei cinco crianças, né? Daí eu fiquei sozinha. Vai fazer três anos que o pai deles faleceu. A minha pequena que tá agora com 2 aninhos, tinha um mesinho quando ele [o pai] faleceu, né? Dai eu fiquei 
com os 4, sozinha. Dai eu pensava assim: O que que eu vou fazer, solita, agora pra lutar, né, com essas quatro crianças? $O$ que eu faço? Eu disse pra mãe, assim: "Me dá vontade de ir no juiz e pegar e entregar tudo. .. ." Daí a mãe disse: "Não, não faz isso. Luta por eles!" Dai eu fiquei. Da gente passar só à água doce e polenta. Passei bastante dificuldade quando eu fiquei sozinha. (M2, 39)

A narrativa denota o sofrimento de uma mãe, que diante das dificuldades de prover os recursos mínimos para a subsistência dos seus filhos, cogita a possibilidade de entrega-los à justiça, almejando que assim possa ser oferecer condições de sobrevivência a eles. Tais dificuldades parecem ser atribuídas, pelo menos em parte, à ausência física do pai, entendido como importante figura para a provisão de recursos materiais.

Concordam com esses dados as discussões sobre as atribuições paterna e materna construídas historicamente em Costa (1983). Nesse contexto, as mães ainda parecem atribuir mais a si mesmas a responsabilidade pela provisão de afeto, e aos pais, a responsabilidade pelo sustento financeiro, confirmando um ideal promulgado historicamente, conforme atesta a narrativa a seguir.

Então, o que ele pode dar mais, como eu posso dizer, é a alimentação. E o amor que ele pode dar mais, assim... Porque ele vem só de noite. Então, o amor dele só mais é de noite. Eu é que tem que estar mais ali em cima, mais na rédea deles é eu. Porque eu passo a maioria do tempo com eles, então é olhando em mim que eles vão... é com o meu jeito que eles vão se expressar, assim, mais tarde. (M4, 22)

No entanto, em função da necessidade de a mulher inserir-se no mercado de trabalho para complementar a renda familiar, as funções culturalmente instituídas parecem deslocar-se (Arpini et al., 2010; Monteiro \& Cardoso, 2001; Wagner \& Levandowski, 2008; Wagner et al., 2005). Ao pai, portanto, em muitas constituições familiares, cabe o espaço doméstico, a responsabilidade de educação dos filhos; lugares historicamente ocupados pela mulher, segundo a narrativa que segue.

É, ele fala uma vez só... Já basta... Porque ele passa mais tempo com eles do que eu. Eu passo mais na rua, catando. Então, com ele já bem mais... Ele grita, ele fala ou ele dá uns tapas e pronto. (M7, 35)

$\mathrm{Na}$ narrativa dessa mãe, salienta-se que a autoridade do pai é compreendida como decorrente do maior contato e convivência dele com o filho, em função da permanência deste ator no espaço doméstico. Segundo relata M7, o fato dela "passar mais na rua" pode ser entendido como explicação para a sua perda de autoridade mediante os filhos.

Além da figura paterna, o lugar ocupado pela avó materna das crianças, como corresponsável no que concerne à provisão dos cuidados necessários à infância, mostra-se muito relevante, concordando com outros estudos sobre o tema (Peres, 2001b; Polli \& Arpini, 2012a). "Claro. Minha mãe já é experiente. Já vai fazer 50 anos. Teve 8 filhos. Tem uma experiência bem grande" (M3, 26).

Além disso, a avó materna destaca-se nas narrativas como a pessoa com quem a família pode contar diante de alguma dificuldade financeira: "É só com a mãe que eu conto. Quando tem dificuldade... A mãe me ajuda bastante. Quando faltam as coisas, eu vou lá, peço pra ela. Se ela tem, vai me ajudando, sabe" (M2, 39).

Ah, já [teve dificuldades]. Deles me pedirem as coisas e eu não ter pra dar... Isso ai é uma coisa que a gente fica muito ... Eles vão pra vó deles, apelam pra ela. Ela dá quando ela tem. (M7, 35)

Evidencia-se, nessas narrativas, que as dificuldades concretas, de provisão de recursos básicos, marcam as vivências das mulheres entrevistadas. Assim, em decorrência da necessidade de buscar o sustento nas ruas, uma das estratégias utilizadas pelas mães do grupo pesquisado, em relação aos cuidados com os filhos, é o aporte nos filhos mais velhos para cuidarem dos mais jovens, diante da inexistência de alternativa.

De manhã, ela passa a manhã toda comigo. Daí eu não saio pra trabalhar. A guria que cuida dela tá no colégio. Dai de tarde eu 
saio e deixo ela com a guria. Me preocupa, porque quando eu estou em casa eu cuido bem dela. Dou mamadeira, dou comida na hora. Dai quando eu saio, eu penso a guria não é assim igual a gente. Só dá mamá. Não dá outras coisinhas pra ela comer. Tenho medo que ela passe dificuldade quando eu não estou. A guria não é experiência, não é igual a gente. Não tem bastante destreza. Não tem. (M2, 39)

Essa narrativa retrata as dificuldades das mães "entregarem o filho" sob cuidados de outrem, por mais que seja alguém do próprio núcleo familiar. Tal ação é realizada, de acordo com os significados atribuídos, na presença de ambivalência, em que, por um lado, há o alívio por ter com quem dividir as funções de cuidado com os filhos, mas por outro, apresentam-se relatos de angústia por não estar desempenhando o papel materno de cuidado direto.

Para a compreensão desse cenário, vale a alusão à caracterização da atividade de coleta e seleção de material reciclável, na qual o trabalhador exerce atividades informalmente, sem garantia de direitos. Nesse contexto, trabalhar é condição sine qua non para a subsistência, de forma que o sujeito é mantido em uma condição de vulnerabilidade social, sem poder contar com recursos que não os de sua própria força de trabalho (Medeiros \& Macêdo, 2006), sendo obrigado a "estar na rua".

Os resultados da presente categoria destacam, assim, que apesar das dificuldades presentes, a rede de relações, representada pela família, é recurso imprescindível para que os cuidados entendidos como necessários aos filhos sejam providos, conforme a compreensão das mães entrevistadas. Embora essas relações sejam reconhecidas por elas como recursos potenciais, aos quais podem recorrer em situações de dificuldade envolvendo os filhos, destaca-se a ideia de que é prioritariamente da mãe a função de cuidado e acompanhamento afetivo.

\section{Considerações Finais}

Os resultados desse estudo permitem ampliar a compreensão acerca das vivências das mães do grupo entrevistado, destacando-se a pluralidade de práticas e concepções emergentes em suas narrativas. Uma das questões evidenciadas nesse trabalho diz respeito à força com que as dificuldades da realidade concreta mostram-se nas experiências das mães participantes. A carência de recursos parece influenciar de forma transversal as concepções acerca dos cuidados necessários à infância. Frente à necessidade das mães buscarem o sustento, é necessário distanciarem-se fisicamente dos filhos, não sendo realizada a imagem historicamente atribuída às mães, como aquelas cujo espaço privilegiado é o doméstico. Assim, diante de um ideal culturalmente promulgado, sub-repticiamente às falas das mães entrevistadas, percebe-se a vivência do sofrimento, mediante a impossibilidade de ocupar em tempo integral esse espaço.

Quanto às ações e estratégias escolhidas para a educação dos filhos, destaca-se a ambivalência das narrativas das mães, que diferenciam o ideal (estratégias verbais) do que consideram possível e efetivo (coerção física). Observa-se, nesse contexto, que independentemente da estratégia utilizada, o que está em jogo é a responsabilização pela educação do filho, almejando a construção de uma pessoa com valores socialmente considerados bons.

De forma concomitante a essas reflexões, se mostra necessário considerar que, mesmo diante de condições adversas, as mães buscam formas de enfrentar as dificuldades. Esse movimento de enfrentamento sustenta-se no complexo sistema de organização e reorganização das relações e nas constantes negociações no âmbito familiar, centralizados na lógica de obtenção ou manutenção de condição para a vida das crianças. Nesse sentido, os filhos parecem representar a continuidade das famílias, o motivo de sua existência.

No marco dessas considerações, entende-se que o presente estudo avança no campo de construção do conhecimento científico, trazendo novos elementos para a compreensão das concepções de mães de grupos populares acerca dos cuidados necessários à infância. No entanto, devem ser consideradas as suas limitações, uma vez que a pesquisa esteve centrada unicamente no universo de mães que integram um grupo 
social específico. Desta maneira, sugere-se a realização de pesquisas que incluam mães de diferentes contextos socioeconômicos e culturais, articulando e comparando perspectivas de atores de diferentes grupos sociais sobre a temática, de forma a ampliar as possibilidades de compreensão do impacto das mudanças e das singularidades que constituem a vivência de cada contexto familiar.

Considerando os argumentos apresentados, o estudo permite apontar para a importância de serem evitadas as concepções estigmatizadoras. Pode-se pensar que, ao dar voz a esses indivíduos no discurso acadêmico/científico, coloca-se em questão concepções instituídas e naturalizadas. Portanto, mediante a possível produção de novos sentidos, em decorrência dos resultados discutidos, este estudo se propõe a subsidiar reflexões sobre o desafio de se trabalhar na seara da saúde, considerando a pluralidade de formas de cuidados e preocupações apontadas pelas protagonistas das narrativas. Nesse contexto, aponta-se a necessidade de revisão do lugar que a psicologia ocupa nos ditames de paradigmas acerca das relações familiares. Pensar os arranjos familiares em seu polimorfismo estrutural parece ser uma alternativa às generalizações e classificações estigmatizantes e rotuladoras, de forma a subsidiar propostas de intervenção para profissionais que trabalham na área da saúde da criança, reafirmando a importância de ações voltadas à promoção da saúde e auxiliando na compreensão do vínculo mãe-criança e do desenvolvimento infantil.

\section{Referências}

Arpini, D. M., Quintana, A. M., \& Gonçalves, C. (2010). Relações familiares e violência em adolescentes em situação de rua. Psicologia e Argumento, 28(63), 325-336.

Bardin, L. (2008). Análise de conteúdo (L. A. Reto \& A. Pinheiro, Trads.). Lisboa, Portugal: Ed. 70. (Original publicado em 1977)

Bilac, E. D. (2002). Família: Algumas inquietações. In M do C. B. Carvalho (Ed.), A familia contemporânea em debate (pp. 29-38). São Paulo, SP: Editora da Pontifícia Universidade Católica de São Paulo.
Bortoli, M. A. (2009). Catadores de materiais recicláveis: A construção de novos sujeitos políticos. Revista Katálisis, 12(1), 105-114. doi:10.1590/ S1414-49802009000100013

Bosi, A. P. (2008). A organização capitalista do trabalho "informal": O caso dos catadores de recicláveis. Revista Brasileira de Ciências Sociais, 23(67), 101-116. doi:10.1590/S010269092008000200008

Bustamante, V., \& Trad, L. A. B. (2007). Cuidando da saúde de crianças pequenas no contexto familiar: Um estudo etnográfico com famílias de camadas populares. Ciência \& Saúde Coletiva, 12(5), 1175-1184. doi:10.1590/S141381232007000500014

Chizzotti, A. (1998). Pesquisa em ciências humanas e sociais. São Paulo, SP: Cortez.

Costa, J. F. (1983). Ordem médica e norma familiar. Rio de Janeiro, RJ: Edições Graal.

Fontanela, B. J. B., Ricas, J., \& Turato, E. R. (2008). Amostragem por saturação em pesquisas qualitativas em saúde: Contribuições teóricas. Cadernos de Saúde Pública, 24(1), 17-27. doi:10.1590/ S0102-311X2008000100003

Gomes, R. (2012). Análise e interpretação de dados de pesquisa qualitativa. In M. C. S. Minayo, S. F. Deslandes, \& R. Gomes (Eds.), Pesquisa social: Teoria, método e criatividade (pp. 79-108). Petrópolis, RJ: Vozes.

Instituto Brasileiro de Geografia e Estatística. (2013). Sintese de indicadores sociais: Uma análise das condições de vida da população brasileira. Rio de Janeiro, RJ: Autor.

Kehl, M. R. (2008). A fratria órfã: Conversas sobre a juventude. São Paulo, SP: Olho DÁgua.

Medeiros, C. V. R., \& Macêdo, K. B. (2006). Catador de material reciclável: Uma profissão para além da sobrevivência? Psicologia \& Sociedade, 18(2), 62-71. doi:10.1590/S010271822006000200009

Minayo, M. C. S. (2010). O desafio do conhecimento: Pesquisa qualitativa em saúde (12. ed.). São Paulo, SP: Hucitec.

Minayo, M. C. S. (2012). O desafio da pesquisa social. In M. C. S. Minayo (Ed.), Pesquisa social: Teoria, método e criatividade (pp. 9-29). Petrópolis, RJ: Vozes.

Moinhos, M. V. C., Lordelo, E. R., \& Moura, M. L. (2007). Metas de socialização de mães baianas 
de diferentes contextos socioeconômicos. Revista Brasileira Crescimento e Desenvolvimento Humano, 17(1) 114-125.

Monteiro, L. P., \& Cardoso, N. A. (2001). Família e criação de filhos. In S. M. G. Sousa \& I. Rizzini (Eds.), Desenhos de família - Criando os filhos: A familia goianense e os elos parentais (pp. 95115). Goiânia, GO: Cânone.

Oliveira, D. S., Rabuske, M. M., \& Arpini, D. M. (2007). Práticas de educação: Relato de mães usuárias de um serviço público de saúde. Psicologia em Estudo, 12(2), 351-361. doi:10.1590/ S1413-73722007000200016

Oros, L. (2009). El valor adaptativo de las emociones positivas. Una mirada al funcionamento psicológico de los niños pobres. Revista Interamericana de Psicologia, 43(2), 288-296.

Peres, V. L. A. (2001a). Concepções de família em população de periferia urbana. In M. M. G. Souza (Ed.), Infância, adolescência e família (pp. 217-230). Goiânia, GO: Cânone.

Peres, V. L. A. (2001b). Desenhos de família. In S. M. G. Sousa \& I. Rizzini (Eds.), Desenhos de família - Criando os filhos: A familia goianense e os elos parentais (pp. 73-94). Goiânia, GO: Cânone.

Polli, R. G., \& Arpini, D. M. (2012a). “A minha família é juntada": A estrutura familiar extensa na visão de crianças de grupos populares. In D. M. Arpini \& A. C. Siqueira (Eds.), Psicologia, famílias e leis: Desafios à realidade brasileira (pp. 143-174). Santa Maria, RS: Editora da Universidade Federal de Santa Maria.

Polli, R. G., \& Arpini, D. M. (2012b). O olhar de meninos de grupos populares sobre a família. $E s$ tudos de Psicologia (Campinas) 29(4), 531-540. doi:10.1590/S0103-166X2012000400008

Richaud de Minzi, M. C. (2004). Development of coping resources in chilhood and adolescence [Special issue]. Interdisciplinaria, 63-74.

Romanelli, G. (2002). Autoridade e poder na família In M. do C. B. Carvalho (Ed.), A família contemporânea em debate (pp. 73-88). São Paulo, SP: Editora da Pontifícia Universidade Católica de São Paulo.
Sampieri, R. H., Collado, C. F., \& Lucio, P. B. (2006). Metodologia de pesquisa. São Paulo, SP: McGraw Hill.

Sarti, C. A. (2004). Família e individualidade: Um problema moderno. In M. C. B. Carvalho (Ed.), A família contemporânea em debate (pp. 39-49). São Paulo, SP: Editora da Pontifícia Universidade Católica de São Paulo.

Silva, M. L., Polli, R. G., Sobrosa, G., Arpini, D. M., \& Dias, A. C. G. (2012). Da normatização à compreensão: Caminhos construídos para $\mathrm{a}$ intervenção familiar. Mudanças, 20(1), 13-21.

Szymanski, H. (2004). Práticas educativas familiares: A família como foco de atenção psicoeducacional. Estudos de Psicologia (Campinas), 21(2), 5-16. doi:10.1590/S0103-166X2004000200001

Wagner, A., \& Levandowski, D. C. (2008). Sentir-se bem em família: Um desafio frente à diversidade. Revista Textos \& Contextos, 7(1), 88-97.

Wagner, A., Predebon, J., Mosmann, C., \& Verza, F. (2005). Compartilhar tarefas? Papéis e funções de pai e mãe na família contemporânea. Psicologia: Teoria e Pesquisa, 21(2), 181-186. doi:10.1590/S0102-37722005000200008

Yazbek, M. C. (2012). Pobreza no Brasil contemporâneo e formas de seu enfrentamento. Serviço Social \& Sociedade, 110, 288-322. doi:10.1590/ S0101-66282012000200005

Yunes, M. A. M., Garcia, N. M., \& Albuquerque, B. M. (2007). Monoparentalidade, pobreza e resiliência: Entre as crenças dos profissionais e as possibilidades de convivência familiar. Psicologia: Reflexão \& Crítica, 20(3), 444-453. doi:10.1590/S0102-79722007000300012

Zanetti, S. A. S., \& Gomes, I. C. (2011). A "fragilização das funções parentais" na família contemporânea: Determinantes e consequências. Temas em Psicologia, 19(2), 491-502. 